\title{
Management of geotechnical hazards through embracing technology and innovative thinking
}

\author{
KT Mandisodza Evolution Mining Ltd, Australia
}

\begin{abstract}
The complex ground conditions at Evolution Mining's Mt Rawdon mine have led to the implementation of a myriad of innovative strategies to combat the ever-present ground control challenges. Ground control strategies implemented include the application of unconventional open pit ground reinforcement methods that are complemented with known and unfamiliar technology-embracing innovative methods. The implemented strategies have been overtly successful in the mitigation of inherent geotechnical risks. These risks manifest as a spectra of failure modes and rockfalls due to inadequate catchment capacity and weak rock mass zones within a diverse rock mass with complex structural controls. Strategies that have been implemented successfully include:
\end{abstract}

- Use of remote drill rigs for blasthole drilling, ground reinforcement drilling and depressurisation drilling.

- Use of an underground cable bolt drill rig in an open pit environment for in-cycle cable bolt drilling, which improves production cycle times.

- Recycling of old dump truck tyres as failure containment walls, complimented with rigid rail steel used as shear pins for crest retention.

The paper outlines some of the challenges that have been encountered during the implementation of the adopted methods and assesses successes and failures of the various applications accordingly.

Keywords: ground control, innovation, technology

\section{Introduction}

Mt Rawdon Operation (MRO) is an active open pit mine in South East Queensland, approximately $75 \mathrm{~km}$ southwest from the coastal city of Bundaberg and $20 \mathrm{~km}$ south-southwest from Mt Perry. The Mt Rawdon open pit is a mature operation that has been through several ownerships. The history of the site is shown in Figure 1.

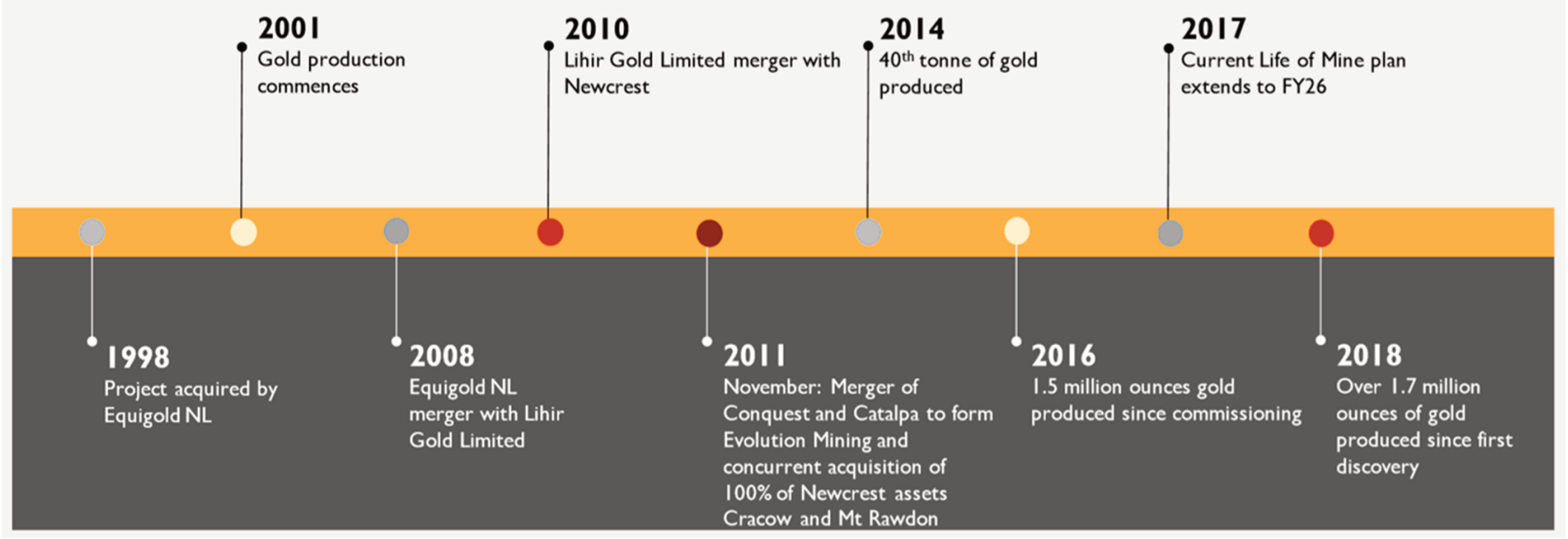

Figure 1 Mt Rawdon's site ownership timeline 
Multiple ownerships have resulted in many different slope design approaches and several iterations of slope stability design work. The mine is a low-grade operation and economic pressures historically motivated most technical decisions (Jele \& Sullivan 2016). Evolution Mining's approach is to extract the resource through safe, low-cost production in an environmentally and socially responsible manner. Mining production is derived from a single open pit, utilising conventional drill and blast, load and haul methodologies, mining 10-15 $\mathrm{m}$ benches. The operation is scheduled to continue until FY25 at current estimates with a remaining life-of-mine (LOM) strip ratio of 2:1.

The open pit is situated within a complex geological and structural setting with variable rock mass quality. The complex geological structure networks within the deposit are associated with various failure modes, with wedge and planar failures dominating across all geotechnical domains. As with most other open pits, the slope design has evolved with time as the understanding of the geotechnical conditions improved and economic factors changed. The implementation of technology has also improved MRO's ability to manage geotechnical risk more effectively.

This paper outlines different innovative strategies undertaken to control slope geotechnical hazards. The strategies implemented were done to ensure the safety of mine personnel and the preservation of the MRO ore reserve and LOM which has remained consistent (minus depletion) for the past three years.

\section{Background information}

MRO site's location is depicted in Figure 2.

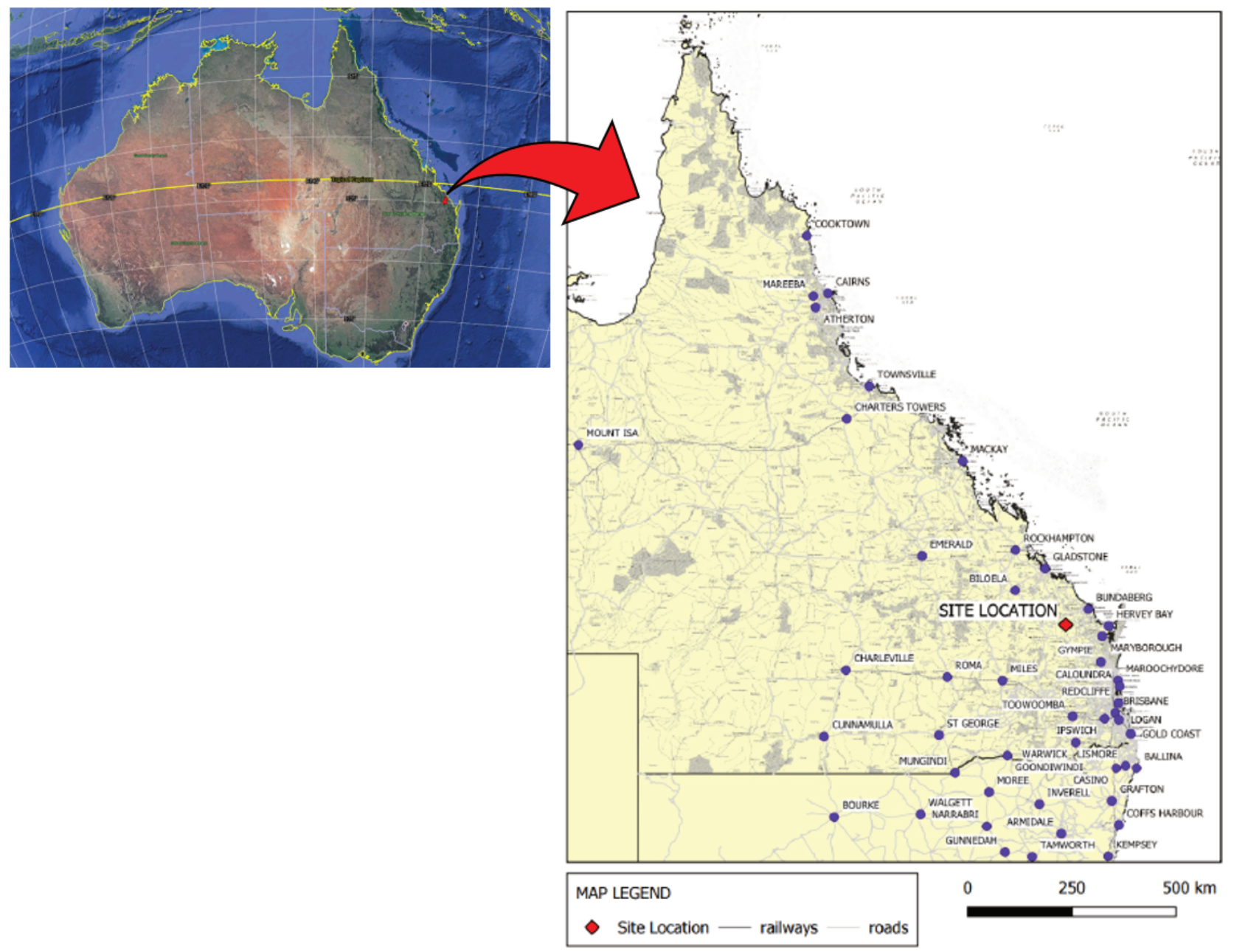

Figure 2 Location of Mt Rawdon mine site 


\subsection{Climate and rainfall}

Mt Rawdon mine lies within the North Burnett region. The Koppen climate classification of the region is subtropical with no defined dry season. High rainfall generally occurs during the summer period, which is typically hot and humid, with an average monthly rainfall illustrated in Figure 3.

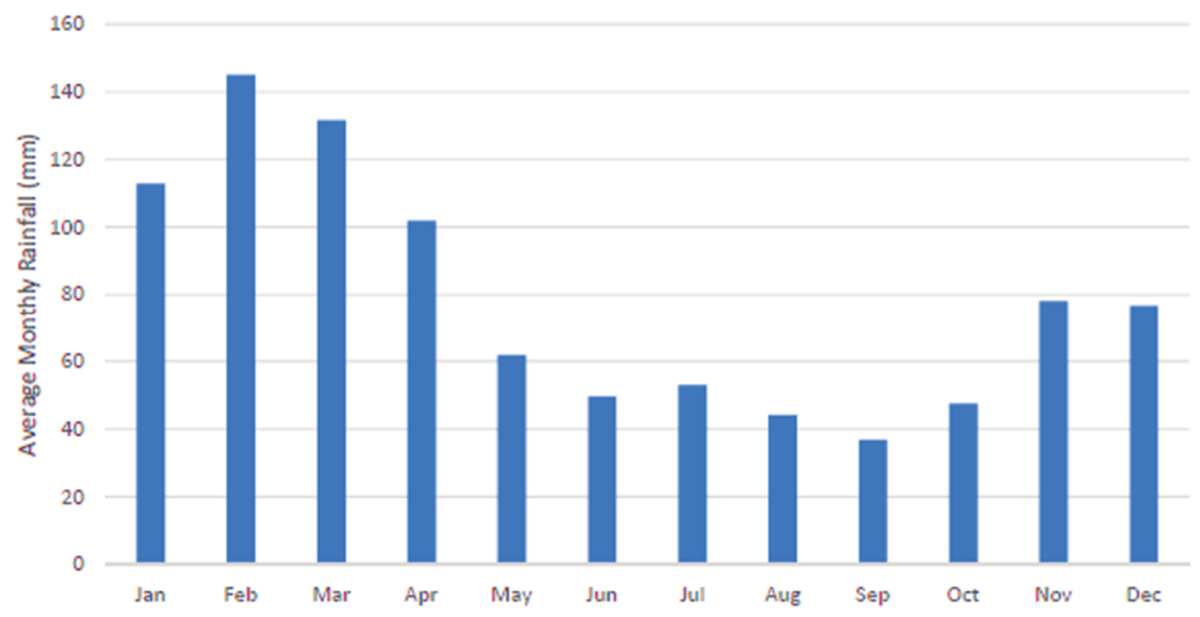

Figure 3 Climatic conditions showing average rainfall

\section{$3 \quad$ Physical setting}

\subsection{Regional geology and structure}

Mt Rawdon deposit is located within the New England Fold Belt, which is the youngest of the Australia continental craton (Buck 2008). The New England orogen is interpreted to be a complex tectonic collage of terrains that accreted onto the eastern margin of Australia in the Late Palaeozoic. The geological region in which Mt Rawdon lies is characterised by three major stratigraphic blocks: (i) the Coastal block (ii) Goodnight block; and (iii) the Gympie block. Mt Rawdon is located within the Goodnight block to the north of the interpreted east-north-east trending Swindon fault and east of the regional north-northwest trending Mt Perry fault. Figure 4 shows the structural elements defining the stratigraphic blocks within and around Mt Rawdon site.

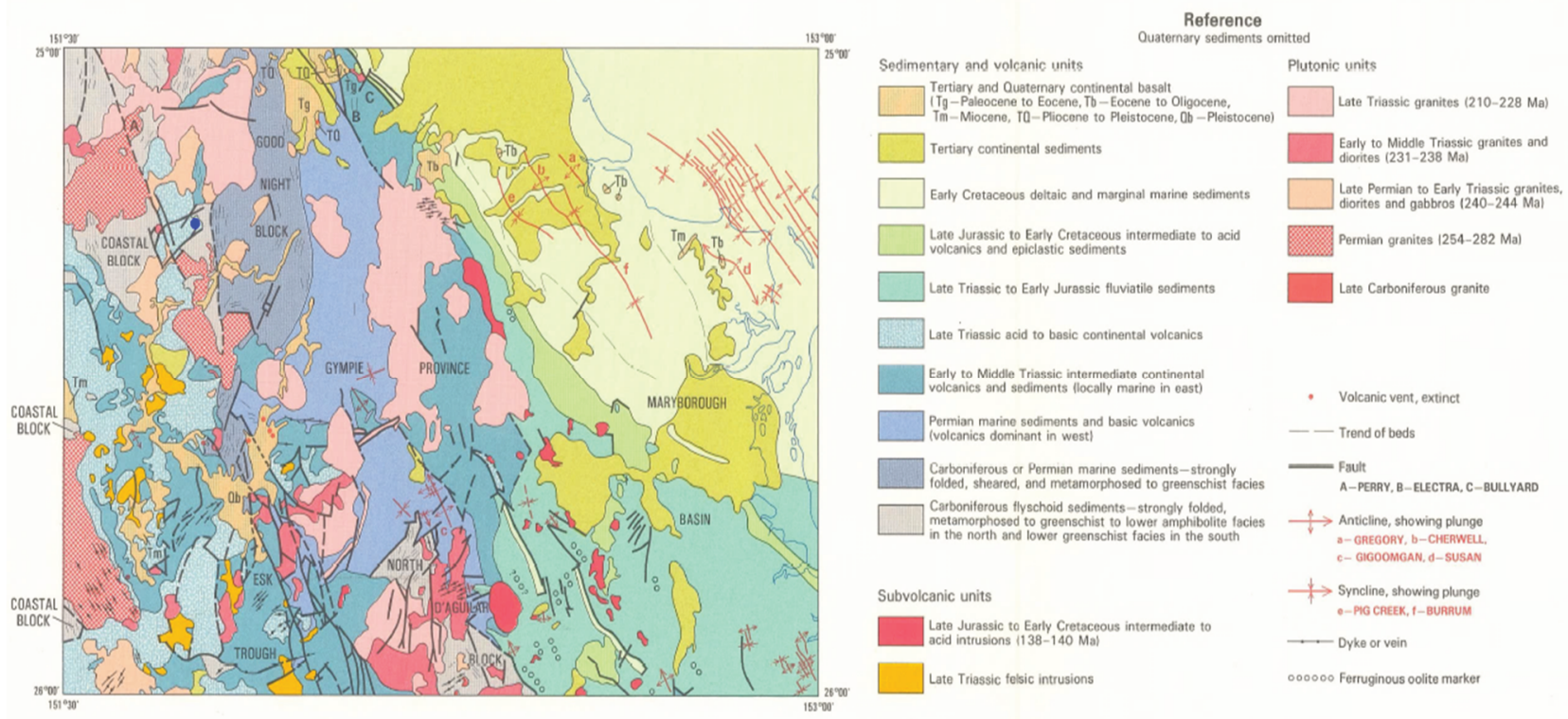

Figure 4 Mt Rawdon regional geology (site location represented by a blue dot) 


\subsection{Local geology and alteration}

Host rocks at Mt Rawdon comprise two dacite domes emplaced within a package of clastic rocks with a strong volcanic association currently traced to a depth of $800 \mathrm{~m}$ (Howard 2015). Suggested origins of these clastic rocks vary from entirely volcano-sedimentary to a significant phreatomagmatic component. According to Duckworth (2014), Mt Rawdon's petrology studies show that the host rocks are clast supported volcaniclastic rock probably derived from an eruption and deposited proximal to the vent.

The orebody is a composite breccia formed marginal to dacite domes emplacement into possibly wet unconsolidated volcaniclastic material both mobilised by phreatomagmatic eruption (Corbett 2019), supporting a strong association between dacite domes emplaced at relatively deep crustal levels and coeval brecciation that provided the open space to host mineralisation.

The local geology for Mt Rawdon is shown in Figure 5.

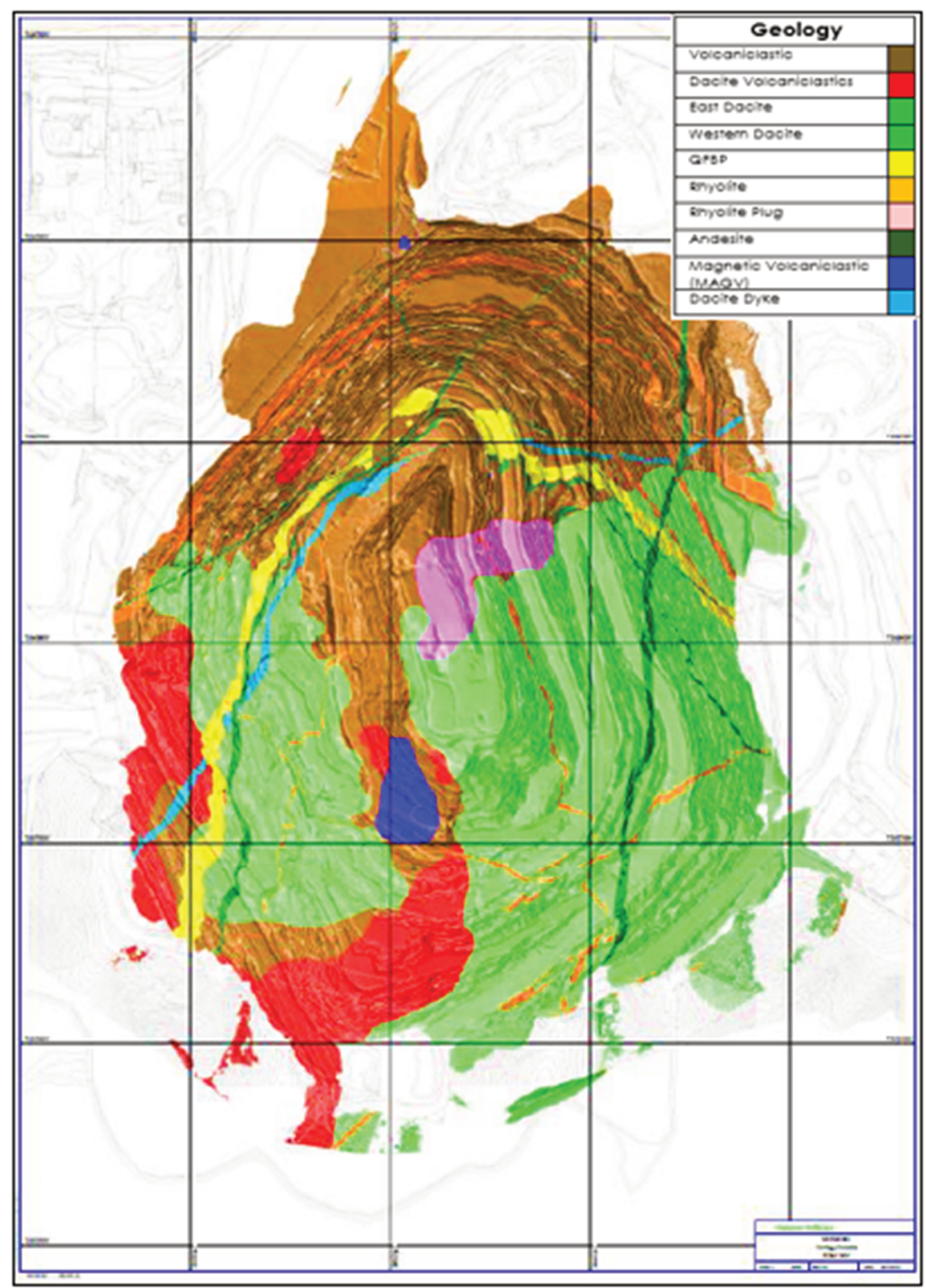

Figure 5 Mt Rawdon local geology 
Hydrothermal alteration is apparent as early prograde propylitic alteration characterised by chlorite-epidote-pyrite (Duckworth 2014) and later retrograde sericite (illite)-carbonate-chlorite-pyrite overprint (Howard 2015). The well-developed sericite near the western dacite dome may be associated with dome emplacement (Corbett 2019). This well-developed sericitic alteration on the western dacite is thought to be the main factor contributing to rock mass behaviour differences and response relative to the eastern dacite unit following excavation. The west wall's characteristic alteration profile compounded by the complex and persistent structural joint sets, particularly the low-angled structural joint set, has played a major role in the ground challenges that have been experienced on the west wall. Figure 6 shows the alteration profile for Mt Rawdon.

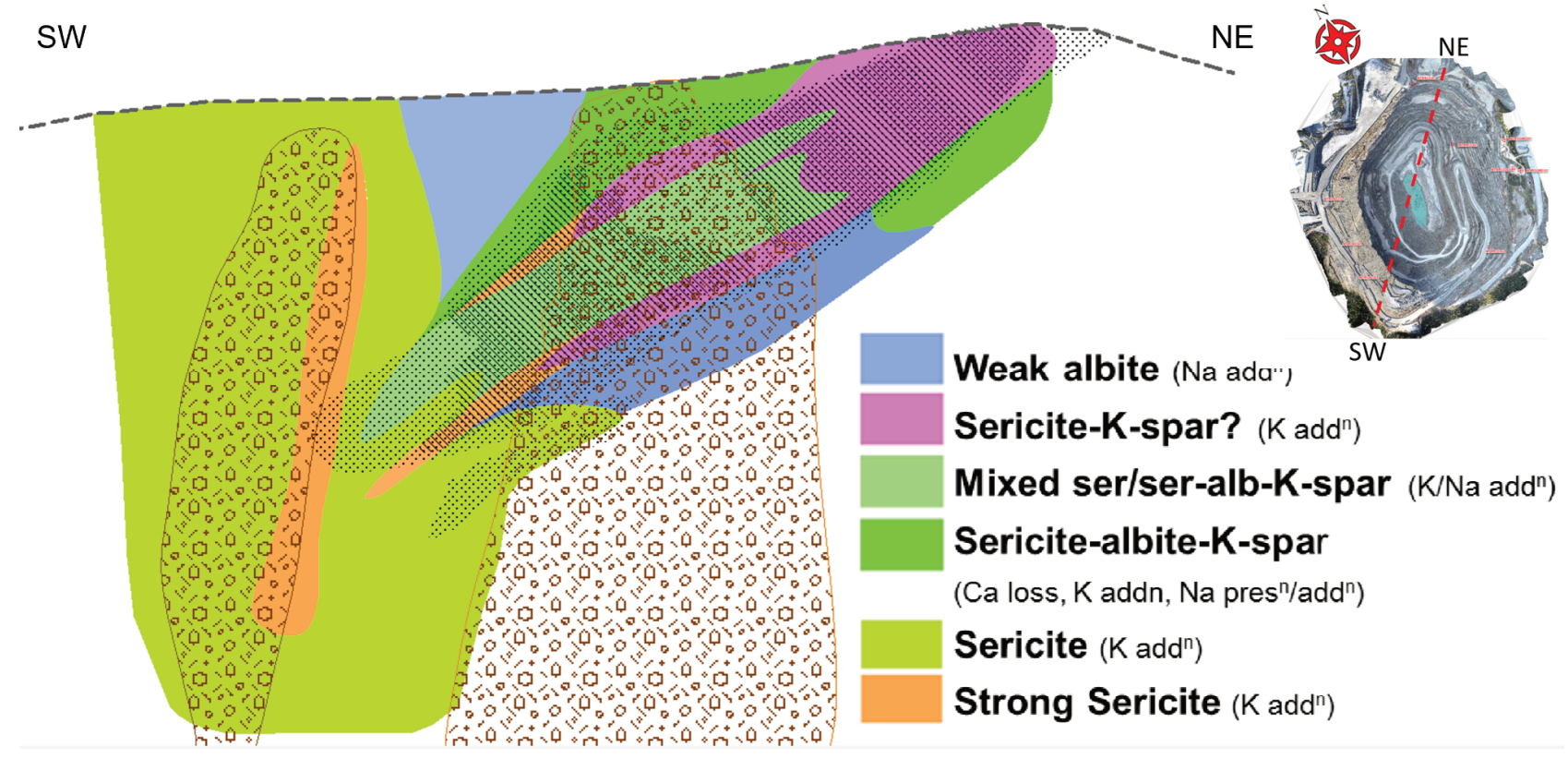

Figure 6 Short wavelength infrared (SWIR) alteration from Mt Rawdon. The initial prograde propylitic alteration characterised by albite and K-feldspar (plus epidote associated with dome-emplacement overprinted by retrograde sericite which dominates near the western dome) (adopted from Corbett 2019)

\subsection{Hydrogeology}

Previously, hydrogeological studies at Mt Rawdon had been constrained by a lack of data nearby the pit. In 2016 and 2017, seven holes were drilled and a series of vibrating wire piezometers were installed. Packer testing was also undertaken when the holes were drilled. SRK Consulting (2017) undertook a review of the hydrogeology with the purpose of providing input into the numerical stability analysis; they concluded the following:

- The groundwater system at Mt Rawdon can be classified as an end-member fractured rock system where bulk permeability is a function of the density, aperture and connectivity of fractures and jointing within the rock mass.

- Matrix permeability is extremely low, likely less than $10^{-10} \mathrm{~m} / \mathrm{s}$ or lower and the aquifer is highly compartmentalised yet shows signs of connection with the surface system.

Aquifer storage and hydraulic diffusivity are extremely low, which subsequently implies that the groundwater in the vicinity of the pit will be extremely high, exhibiting a steep cone of depression.

A depressurisation program to pushback the phreatic surface by $50 \mathrm{~m}$ from the immediate pit wall is currently ongoing through the implementation of $100 \mathrm{~m}$ long depressurisation holes on a $50 \mathrm{~m}$ by $30 \mathrm{~m}$ (bench/batter height) grid spacing. Groundwater hydrostratigraphy units have been represented as domains and developed as part of the geotechnical model (see Table 1). 
Table 1 Mt Rawdon hydrostratigraphic units (SRK Consulting 2017)

\begin{tabular}{lll}
\hline Domain & Hydrostratigraphic unit & Hydraulic conductivity, $\mathbf{~} \mathbf{~ m} / \mathbf{s})$ \\
\hline 1 & Massive rock & $1 \times 10^{-11}$ \\
2 & Very large blocky rock & $1 \times 10^{-10}$ \\
3 & Blocky rock & $1 \times 10^{-9}$ \\
4 & Small (to medium) blocky rock & $1 \times 10^{-9}$ \\
5 & Friable and very small blocky rock & $1 \times 10^{-9}$ \\
\hline
\end{tabular}

The hydrogeological model was developed through a review of available data including, previous hydrogeological assessments, previous drilling results and available groundwater monitoring bores of which some include vibrating wire piezometers (VWP). Analysed hydrogeological information led to the development of a conceptual groundwater model for the site and the creation of a phreatic surface for incorporation into pit slope stability modelling and recommendations for groundwater depressurisation.

Reviewed VWP data indicated an improved impact of the mining operations on the groundwater level in the vicinity of the pit wall. It was thus concluded that:

- Pore pressures in the vicinity of the pit are relatively stable over the period recorded.

- VWP patterns are consistent with an unconfined aquifer and indicative of a highly compartmentalised groundwater system.

- The stability over time indicated very low matrix permeabilities.

\section{$4 \quad$ Geotechnical model}

The geotechnical model has evolved over time and includes data from laboratory testing, cored drill holes, conventional and photogrammetric pit mapping. The geotechnical model was updated in 2016 by Pells Sullivan Meynink (PSM) (2017) as part of a slope design assessment. The rock mass was characterised based on the main rock types as well as into three rock classes or geotechnical domains based on rock mass characterisation and structures. Jele \& Sullivan (2016) describe the geotechnical environment based on the PSM work.

Further refinement was undertaken in 2017 by SRK Consulting who undertook pit mapping of accessible areas. In addition to using conventional rock mass classification systems, they also used the ground blockiness index (GBI): a method that was developed as a rapid mapping system for recording general geotechnical conditions (Walker \& de Bruyn 2006). Based on this work, the Mt Rawdon pit has been separated into five main geotechnical domains as shown in Figure 7. These domains reflect the rock mass quality and characteristics and are not constrained by rock type boundaries. Table 2 is a summary of the rock mass characterisation for the geotechnical domains. 


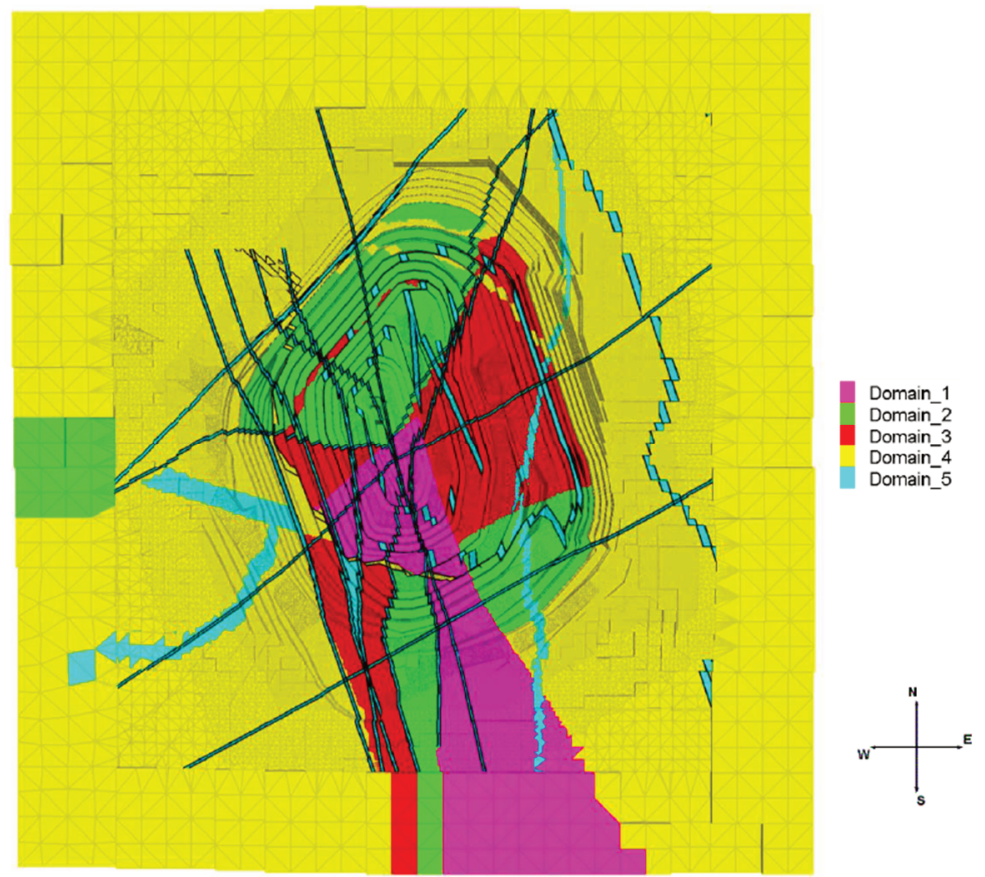

Figure 7 Mt Rawdon geotechnical domains

Table 2 Mt Rawdon geotechnical domains characteristics (SRK Consulting 2017)

\begin{tabular}{lllllllllllll}
\hline Domain & GBI & & GSI & \multicolumn{3}{l}{$\begin{array}{l}\text { RMR } \\
\text { Bieniawski }\end{array}$} & $\begin{array}{l}\text { RMR90 } \\
\text { Laubscher }\end{array}$ & $\begin{array}{l}\text { Hardness/strength } \\
\text { (MPa) }\end{array}$ & $\begin{array}{l}\text { Suggested } \\
\text { mi }\end{array}$ \\
\hline 1 & M & $2-3$ & C & 82 & C & 90 & C & 78 & C & 130 & 25 \\
& S & $1 \& 4$ & LB & 65 & LB & 70 & LB & 62 & LB & 100 & \\
2 & M & 4 & C & 78 & C & 83 & C & 75 & C & 130 & 25 \\
& S & $3 \& 5$ & LB & 55 & LB & 65 & LB & 58 & LB & 100 & \\
3 & M & 5 & C & 70 & C & 80 & C & 68 & C & 120 & 25 \\
& S & $4 \& 6$ & LB & 53 & LB & 62 & LB & 60 & LB & 100 & \\
& M & $6-7$ & C & 45 & C & 50 & C & 38 & C & 90 & 20 \\
& S & 5 & LB & 35 & LB & 40 & LB & 30 & LB & 50 & \\
& M & $7-8$ & C & 35 & C & 40 & C & 30 & C & 50 & 15 \\
& S & 5 & LB & 25 & LB & 30 & LB & 20 & LB & 30 & \\
\hline
\end{tabular}

$S=$ subsidiary index value, $M=$ main index value,$L B=$ lower bound value, $C=$ characteristic value

The geotechnical domains are defined as below:

- Domain 1: Massive rock.

- Domain 2: Very large blocky rock.

- Domain 3: Blocky rock.

- Domain 4: Small to medium blocky rock.

- Domain 5: Friable and very blocky rock.

The five domains are characterised by four main structural sets shown in Table 3. 


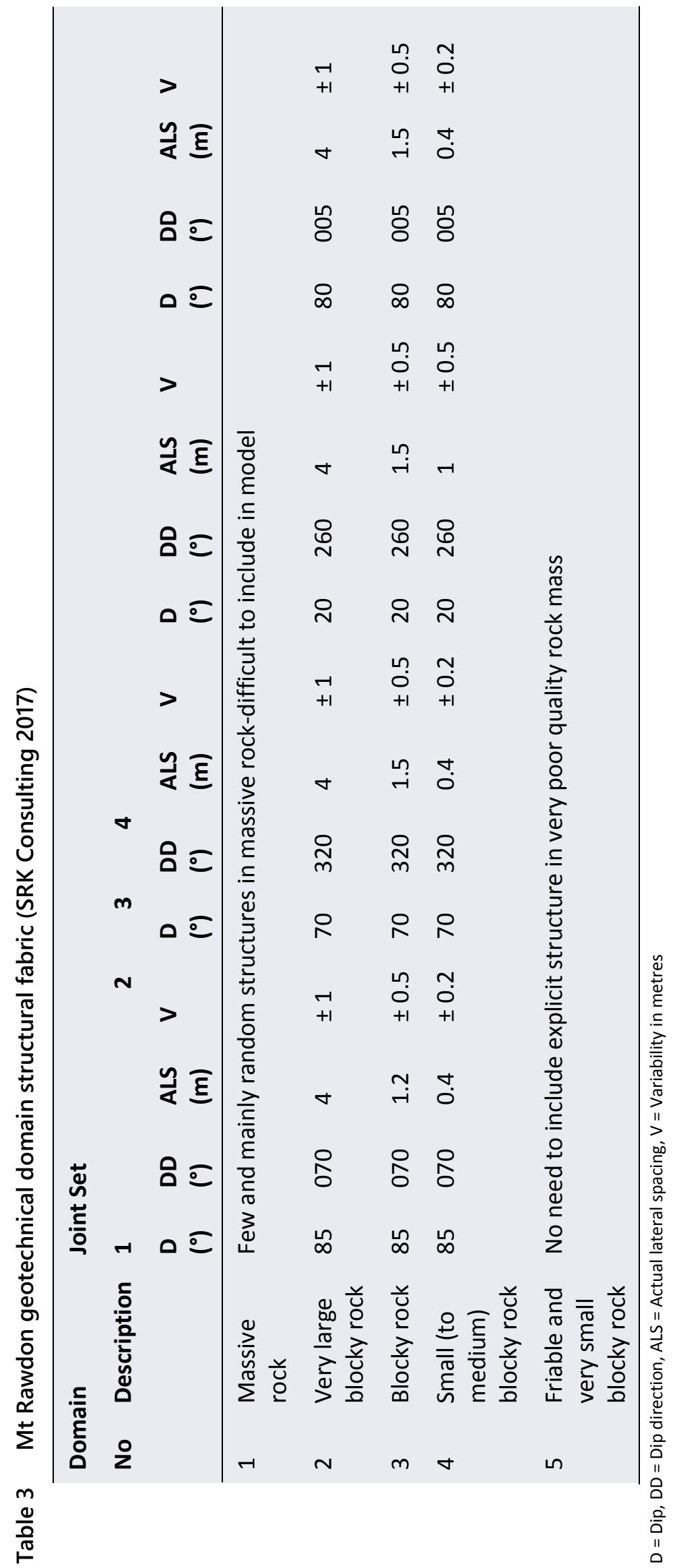




\section{$5 \quad$ Ground challenges}

Slope management challenges include rockfalls, bench scale to multiple bench slope failures and instabilities have consistently been experienced throughout the life of Mt Rawdon. These geotechnical risks have been managed at different scales depending on the location of the rockfall or failure relative to pit activities at the time of the failure. However, three significant events (i.e. slope failures) have led to the implementation of innovative strategies to manage slope challenges.

The ground control management plan developed for Mt Rawdon pit highlights the strategies that have been adopted to manage the geotechnical risk that is typical to the pit slopes. Strategies that have been adopted include:

- Progressive pit wall mapping to understand the structural networks as new exposures surface through pit development.

- Implementation of trigger action response plans for working near highwalls for risk management.

- Full pit monitoring through slope radars for real-time monitoring.

- Installation of more robust instruments in nested piezometers.

- Time-domain reflectometer.

Remote drilling has also been adopted for drilling in high-risk areas. All these slope management strategies have complemented each other to provide an improved slope risk management system.

Ground control challenges are mainly a result of the complex geology of the deposit, the geometry of the pit relative to the inherent structural networks and operational issues. Jele \& Sullivan (2016) presented data for the Mt Rawdon open pit structural orientations and slope wall orientations in the stereographic projections shown in Figure 8. A brief description of the three slope failure events and the implemented solutions are provided in the following section.

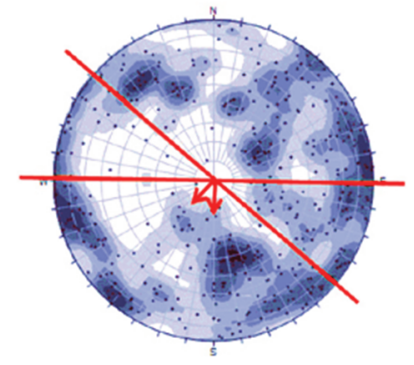

(a)

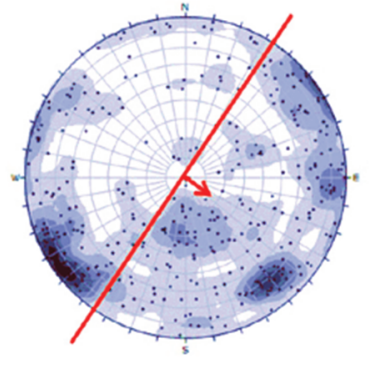

(b)

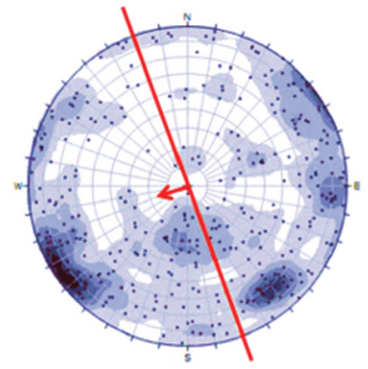

(c)

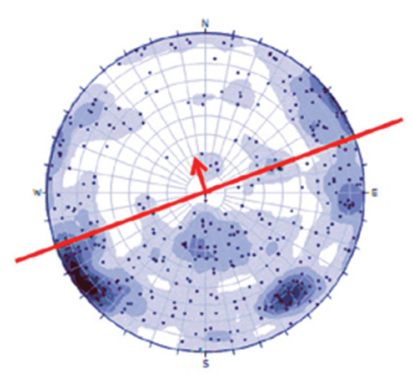

(d)

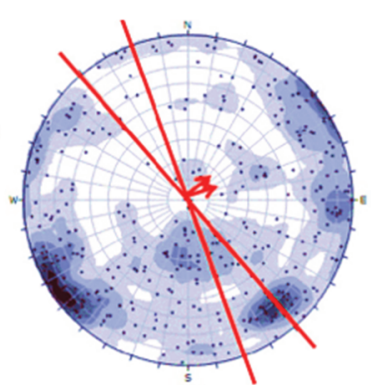

(e)

Figure 8 Mt Rawdon geotechnical stereographic plots showing structural orientation and pit wall orientation (red lines) for different slope faces. (a) North wall; (b) Northwest wall; (c) East wall; (d) South wall; and (e) West wall (after Jele \& Sullivan 2016) 


\subsection{West wall failure: 10 March 2018}

On 10 March, whilst mining a ground support pad that was constructed to access areas not easily reachable for an excavator, a planar failure of approximately 4,500 t occurred on the west wall. The material flow from the failure contacted the excavator and resulted in a significant incident being recorded (see Figure 9).

This failure was bounded by two primary joints with attitudes (dip/dip direction) of 60/120 and 75/020, respectively, and occurred along a dominant basal plane with an attitude of 35/070. This incident initiated the innovative change process for managing geotechnical hazards at MRO.

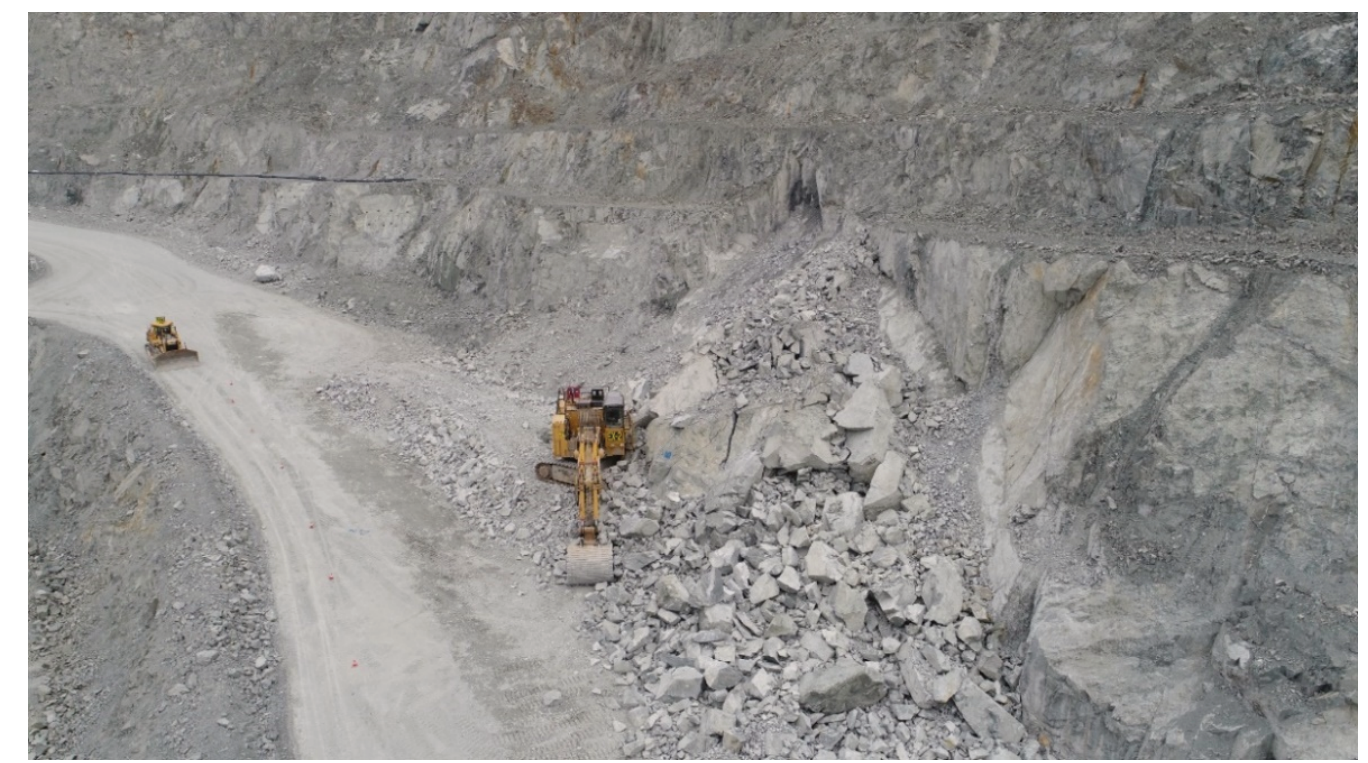

Figure 9 West wall planar failure, 10 March 2018

Following the incident, two options were considered to remediate the failure.

The first option proposed the mining of the failure material, stepping out and redesigning the pit slope from that point. This proposal included a wider berm at the $45 \mathrm{mRL}$ and revising the reserve pit design to assume a 45-degree inter-ramp angle for subsequent benches below the failure location.

Considering the amount of sterilised gold ounces that would have been lost by adopting this option, an alternative solution was considered which included an adapted, unconventional ground support regime. Although this option deferred ounces to a future date, it did not have anywhere near the negative impact to the LOM net present value when compared to the first proposed option.

Considering the fall of ground risk potentially posed by the failure to mining of lower benches, and the extent of the basal plane on the west wall (attitude 35/070), an option to contain future failure material and shear-pinning of similar structures on the lower benches was proposed. Failure remediation involved placement of used haul truck tyres and rail steel acting as shear pins.

A total of 35 rail steels were installed over a $100 \mathrm{~m}$ lateral distance with holes drilled to various depths ranging from 16 to $5 \mathrm{~m}$ to the ramp grade leaving a $3.5 \mathrm{~m}$ protrusion. The embedded portion of the rail steel served to reinforce the batter, providing shear resistance across joints. Tyre diameters ranged between 3.6 to $3.2 \mathrm{~m}$ respectively were placed over the protruding rail steel to cover the $100 \mathrm{~m}$ lateral distance. The installation process involved fish plates to connect the rail steel, a crane to lift the rail lengths and placing them in $203 \mathrm{~mm}$ diameter hole sockets which were subsequently grouted. A tyre handler was used to lift the tyres and place them over the $3.5 \mathrm{~m}$ protruding rail steel to form a wall retainment structure (see Figure 10(a)).

The tyre wall structure enabled the resumption of mining activities below the west wall failure without a change in the deliverable ounce-profile out of the reserve pit shell. The completed tyre wall structure is shown in Figure 10(b). 


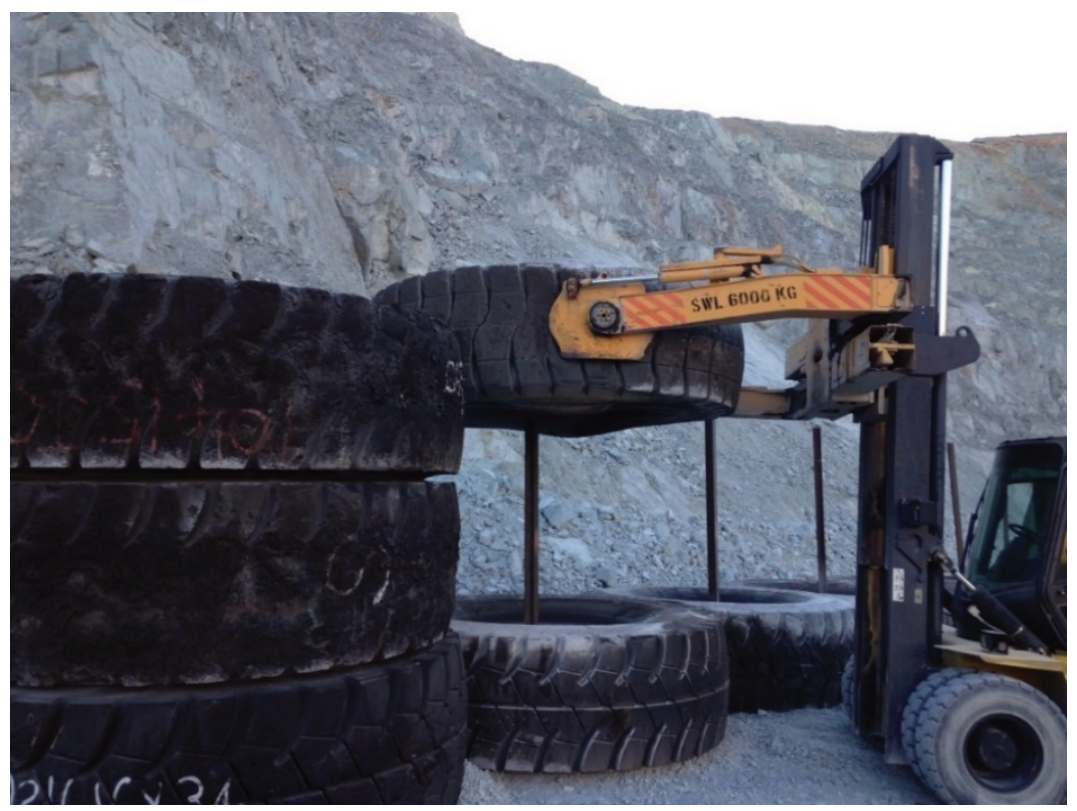

(a)

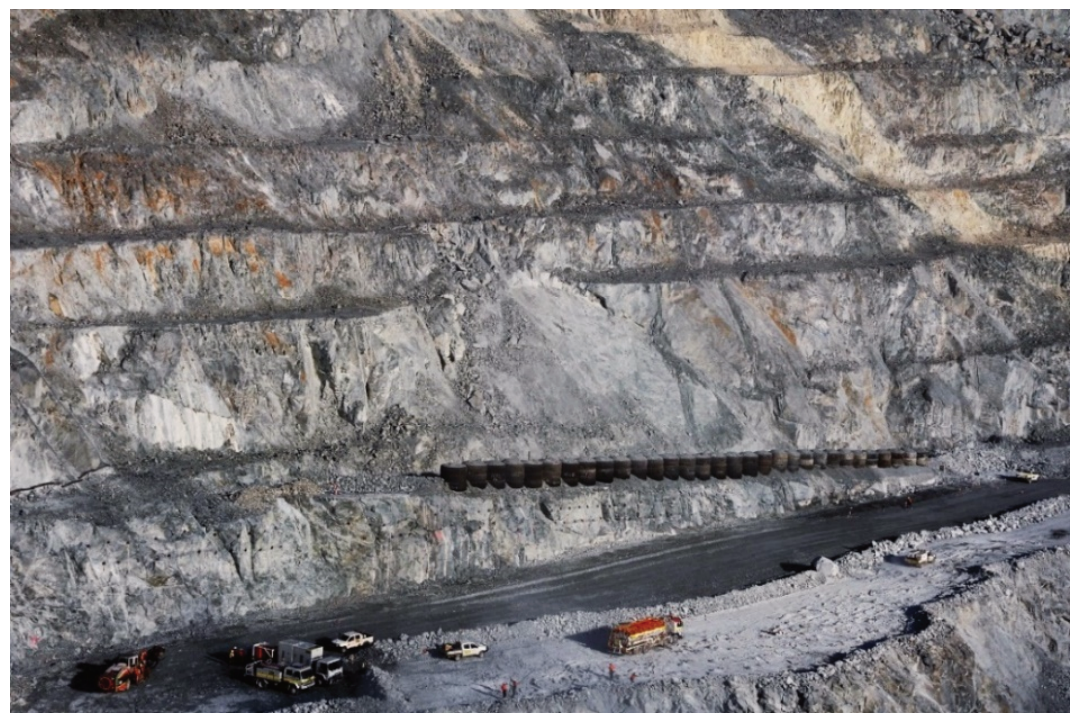

(b)

Figure 10 West wall (a) during and (b) after failure clean-up and construction of a tyre wall

Ground support in the form of cable bolting has been routinely used in the Mt Rawdon Pit (Jele \& Sullivan 2016). With the prevalence of unfavourable structure on the west wall, significant cable bolting was deemed to be the most appropriate control measure to prevent local bench scale failures. There was also a requirement to have quicker cycle times between ground support installation and production. This occurred with the introduction of an underground cable-bolter to improve cable bolting efficiency. Figure 11(a) shows the cabolter at work. The cabolter's ability to drill, install and grout a total of $200 \mathrm{~m}$ of cable bolts per shift, provided optimal cycle times between ground support and production. Though the cabolter provided in-cycle drilling and safer installation of cablebolts, it also contributed to a delayed bench turnover from slow installation of cable bolts when compared to conventional double benching and wall scaling during the mining cycle.

Challenges encountered with the cable bolting solution through the use of an underground rig included water supply for drilling, compressed air and power supply in an open pit setup. According to DS421 model cabolter specifications (https://www.rocktechnology.sandvik), the cabolter requires water for flushing. The water 
pump operates up to $100 \mathrm{l} / \mathrm{min}$ at a pressure rating between 10 to $15 \mathrm{bar}$ and the air compressor operating at 7 bar. The electric system for the rig requires 50 to $60 \mathrm{~Hz}$, with total installed power of $75 \mathrm{~kW}$. To overcome these challenges, innovative solutions had to be implemented to realise the full potential of the cabolter in an open pit environment. Innovation came through equipment that was outsourced from different vendors to complement the cabolter. A 600 kilo-volt-ampere (kVA) 415/1100 transformer, a 350 kVA $415 \mathrm{~V}$ diesel generator and a 12 cubic metre per minute compressor for air supply, were leased by the mine site for the cabolter. The transformer and diesel generator were mounted on a truck and the compressor was a standalone unit. Water was supplied from an old fire truck, with a 3,000 L capacity tank. The water tank had to be topped-up in-between drilling cycles to ensure that a constant supply of water was maintained.

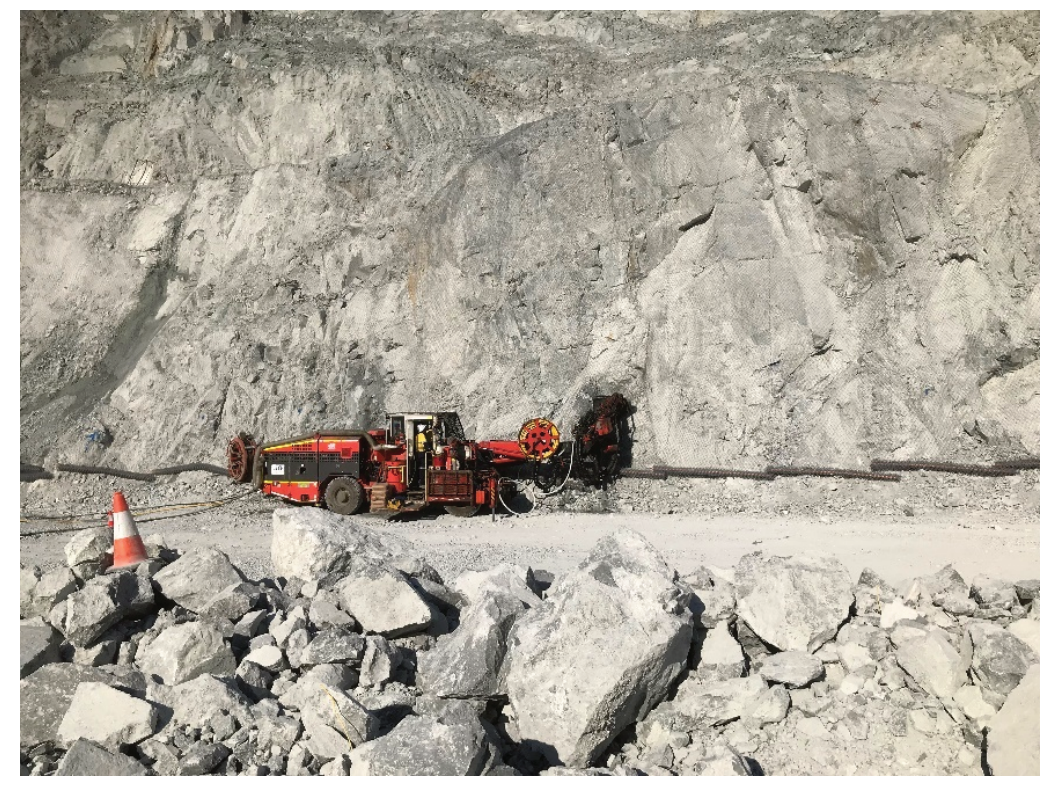

(a)

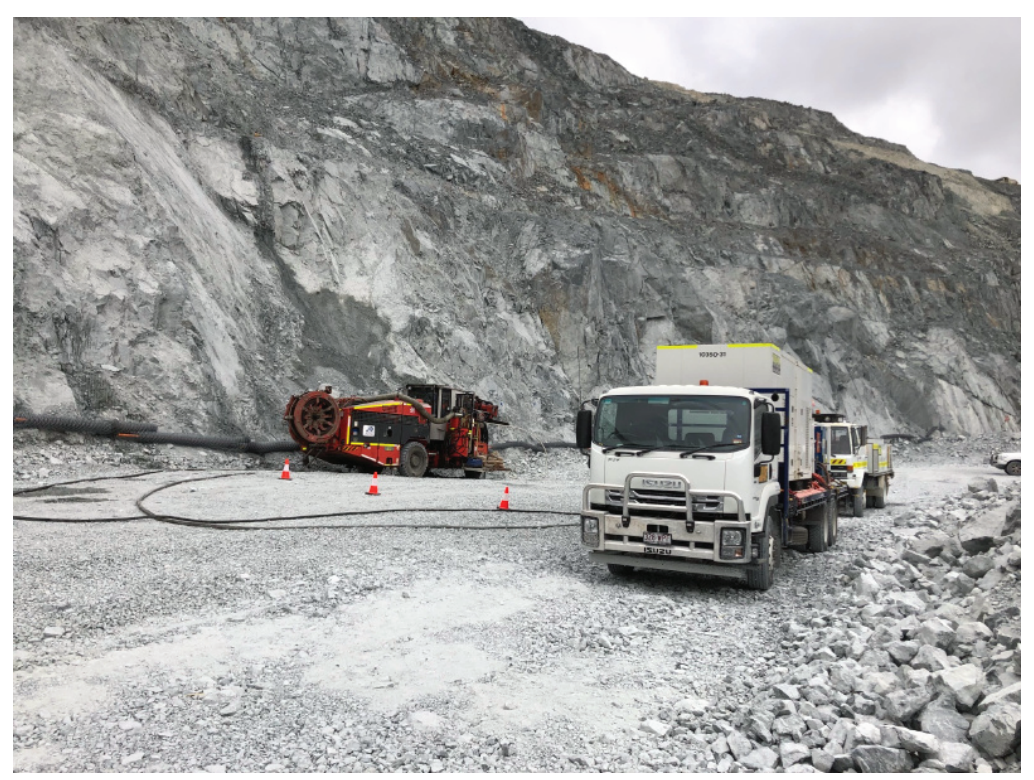

(b)

Figure 11 (a) Underground cabolter working in an open pit environment; and (b) Cabolter with a generator for power supply, compressor for air supply and water supply for flushing 


\subsection{Southwest wall instability: 13 October 2018}

From 10 to 13 October 2018, a total cumulative rainfall of approximately $230 \mathrm{~mm}$ was received onsite, with rainfall intensity ranging between 50 to $100 \mathrm{~mm} / \mathrm{hr}$. The rainfall events induced an inter-ramp instability, bounded by two structures that formed a wedge. The total volume of the material contained within the wedge was calculated to be $400,000 \mathrm{~m}^{3}$ (approximately $1.1 \mathrm{Mt}$ ).

The instability was identified through the active slope radar monitoring. Total cumulative displacements within the unstable area ranged between 100 to $500 \mathrm{~mm}$, with an average displacement of $150 \mathrm{~mm}$ within the moving mass. Tension cracks were also observed on the surface of the main pit access. Figure 12 shows the slope radar displacement map recorded during the event.

Subsequent to this event, a preliminary analysis of satellite radar data from interferometric synthetic aperture Radar (InSAR) indicated that small wall movements had occurred several months prior to the instability manifesting itself (shown in Figure 13).

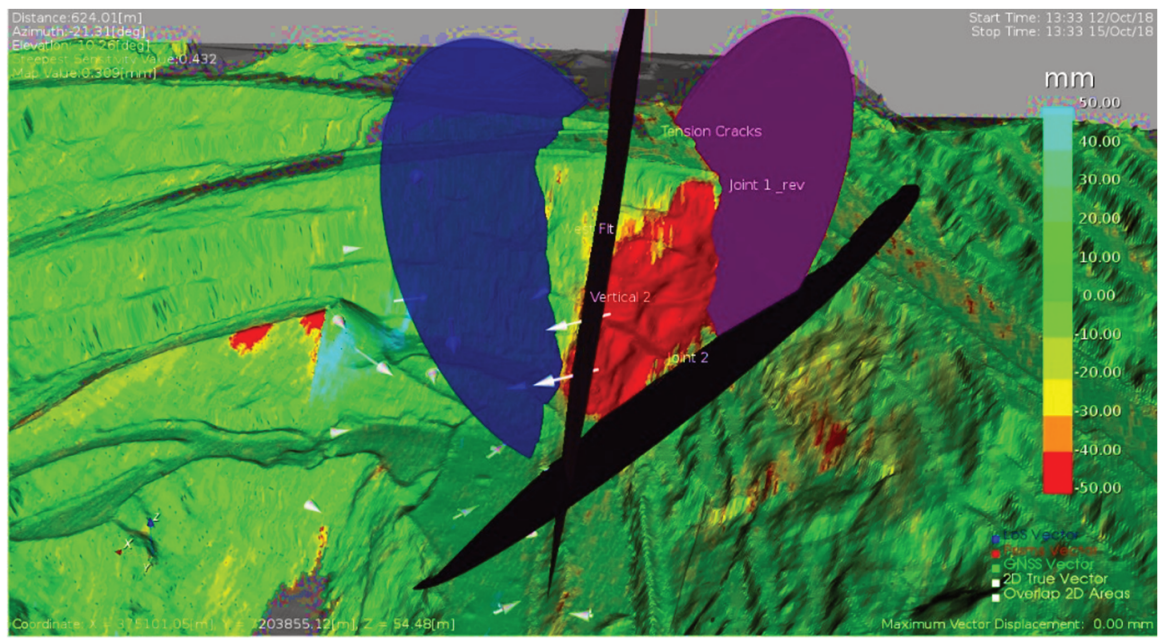

Figure 12 Radar map showing southwest wall total cumulative displacement from 12 to 15 October 2018

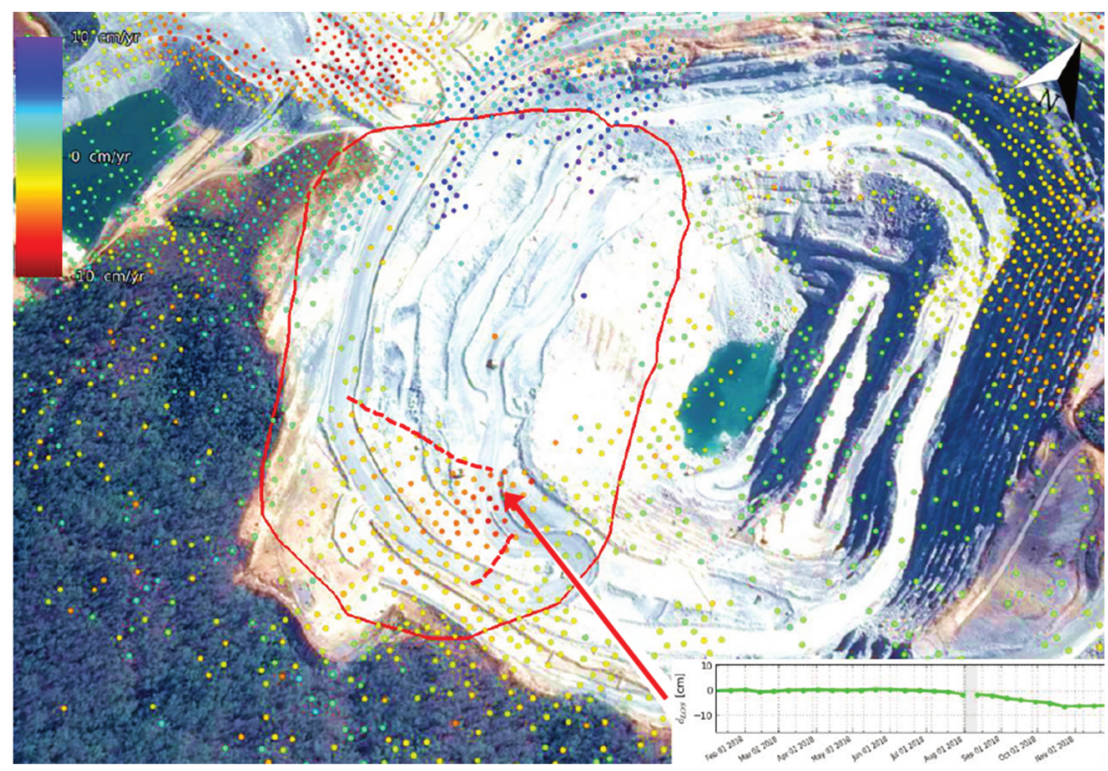

Figure 13 Southwest wall InSAR monitoring - January to November 2018

A back-analysis of the failure was undertaken by Itasca (Wines 2018) using Itasca's three-dimensional distinct element code (3DEC) (Itasca 2017). The model included explicit joints and different phreatic surface scenarios considered to simulate groundwater conditions as recorded by piezometers. The modelling results indicated 
that a $5 \mathrm{~m}$ raise in the phreatic surface caused an instability in the model to resemble what was delineated by the slope radar monitoring. Figure 14 shows the total displacement and velocity contours for the southwest failure for the 3DEC numerical model. Given the scale of this instability and uncertainty around the timing of potential failure, a decision was made to cut back the wall to improve stability.

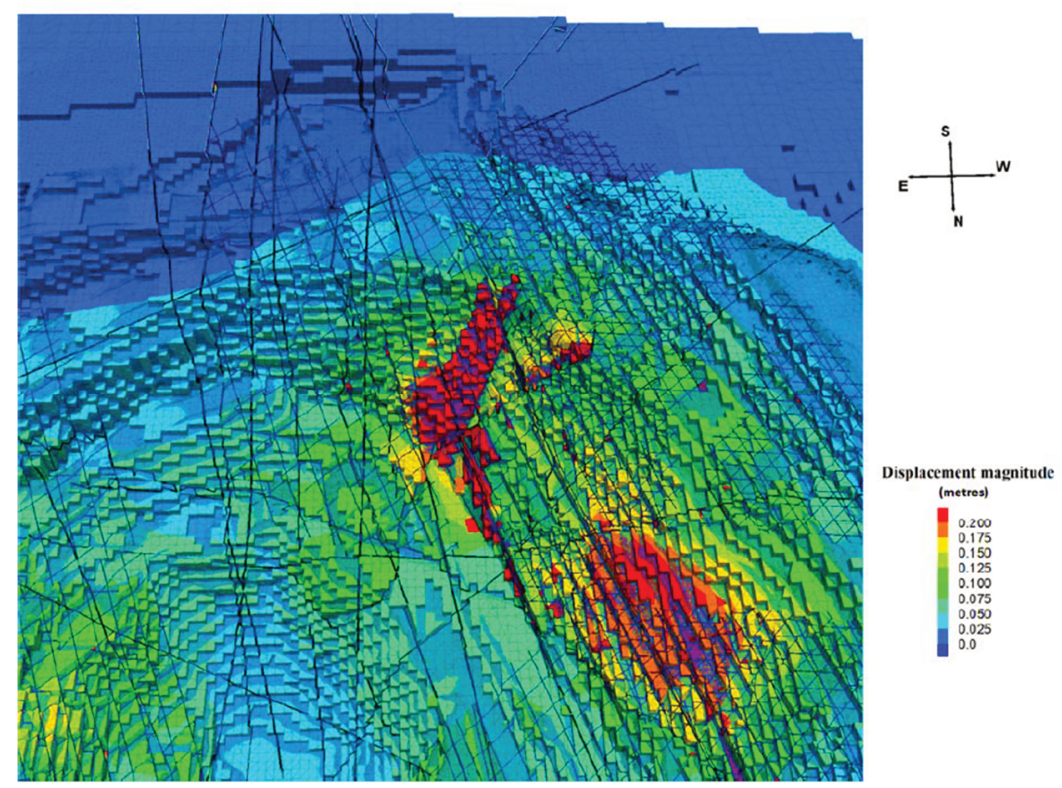

(a)

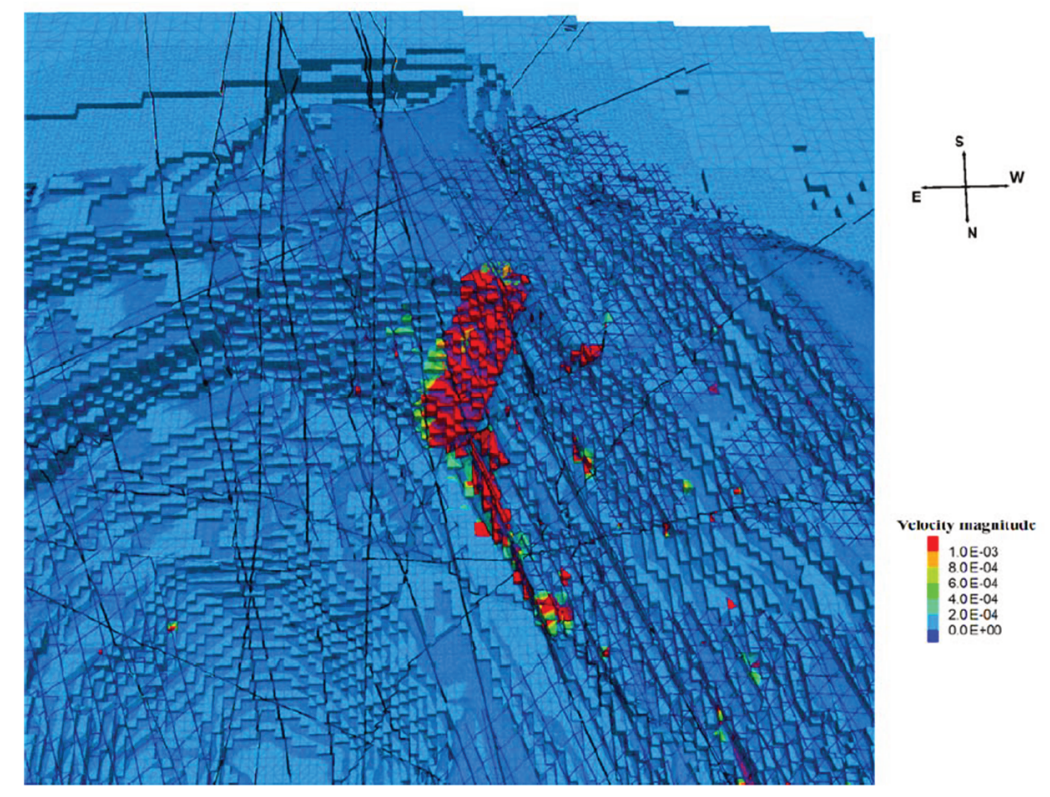

(b)

Figure 14 (a) 3DEC cumulative displacement contours after current pit excavation, with the phreatic surface raised by $5 \mathrm{~m}$ for the faults and the joints; and (b) 3DEC numerical model velocity contours after current pit excavation, with the phreatic surface raised by $5 \mathrm{~m}$ for the faults and the joints

\subsection{West wall instability: 17 July 2019}

Innovative ideas have always been driven by the myriad of slope challenges at Mt Rawdon mine through the mining process. On 17 July 2019, another ground control challenge manifested on the west wall of the pit. Below the retaining wall that had previously been constructed to contain the failed material recorded in 
March 2018, another batter-scale failure was recorded. Two ground-based radars started picking up trends on a block of rock that was controlled by two sub-vertical joint sets and a shallow dipping basal plane.

Figure 15 shows a view of the west wall looking across from the north wall. The basal plane appeared to have similar characteristics, though slightly steeper due to undulation, to the basal plane that had been exposed on the bench above. Considering the crest loss that had been experienced on the intermediate bench between the crest, where the tyre wall was constructed, and the toe of the $0 \mathrm{mRL}$ position, it was critical to stabilise the failure and prevent a 'domino-effect'. A slide analysis indicated that a $20 \mathrm{~m}$ high and $150 \mathrm{~m}$ long buttress was required to stabilise the potential instability and counteract the driving force.

A remote dozer was hired to construct the stabilising buttress, which was a first for the site. The remote dozer's ability to work in high hazardous areas provided a safer option to limit the exposure to mine personnel below the west wall instability. This action ensured that the mitigation measure (i.e. the buttress) was implemented safely. Figure 16 shows the remote dozer in operation during construction of the west wall buttress.

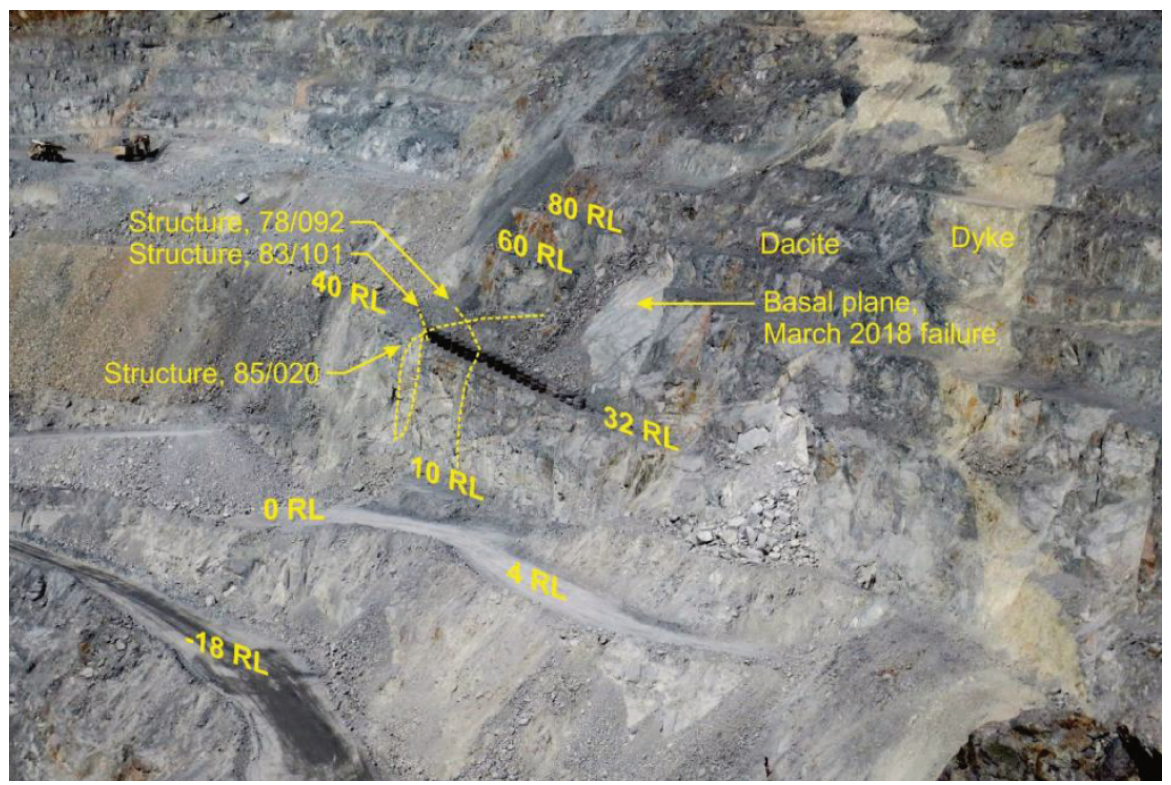

Figure 15 View of the west wall looking from the north wall

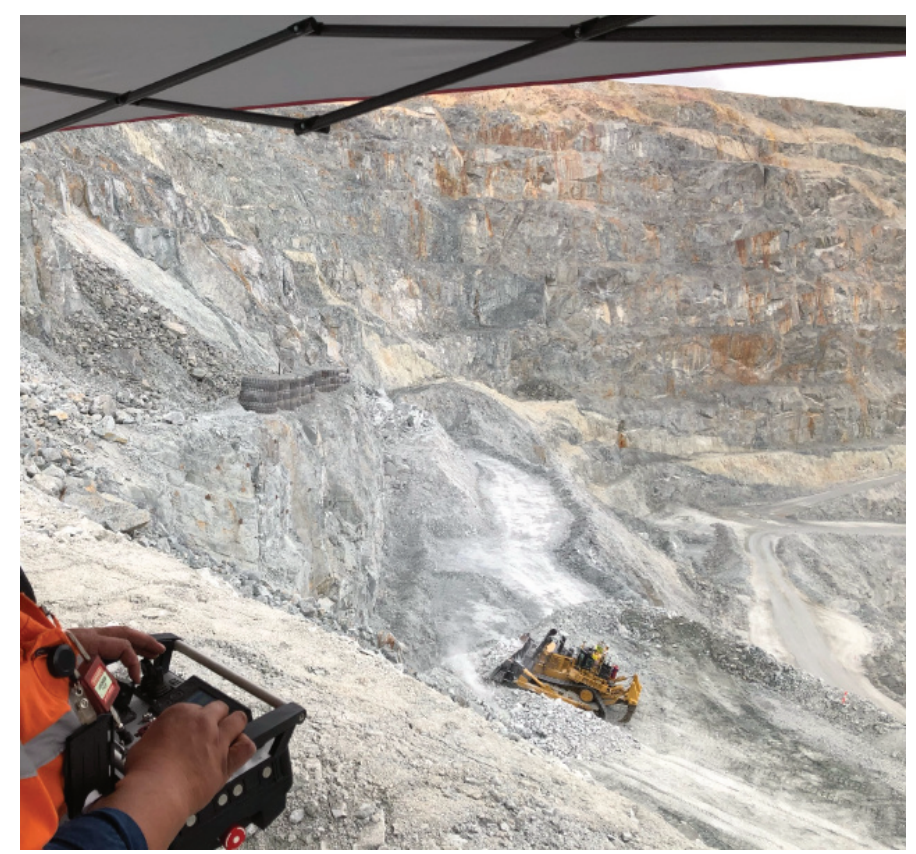

Figure 16 Remote dozer working on the west wall 


\section{Conclusion}

Slope geotechnical risk management challenges at Mt Rawdon have initiated some innovative ideas to mitigate slope stability risks. Some of the innovative ideas have been unconventional and others have managed to embrace technological advancement in managing ground control risks. Implementation of these innovative ideas has not been met without inherent challenges; several secondary challenges have been encountered during practical applications and have been managed to ensure that each innovative idea could be explored to its fullest.

Challenges with implementation ranged from the use of the underground operation's cabolter wet drilling method when installing cable bolts to in-pit Wi-Fi mesh network inadequacy to support remote drill rigs. All these challenges paved the way for more ideas to be brainstormed until convergence of suitable solutions was attained.

Evolution Mining's position is to realise the full exploitation of the resource in a risk-averse manner, regardless of Mt Rawdon site's operational maturity and complex structural geology. Continued use of innovation and embracing technology will be instrumental in managing mining activities through the application of risk assessment principles and processes. This is essential to prevent accidents, injuries and minimising geotechnical related risks and slope ground control challenges.

\section{References}

Buck, A 2008, The Mt Marcella Volcanics: middle Triassic convergent margin volcanism in southeast Queensland, MSc Thesis, Queensland University of Technology, Brisbane.

Corbett, GJ 2019, Comments on the Geology Exploration Potential of the Mt Rawdon Gold Mine, NE Australia, unpublished.

Duckworth, R 2014, Petrology report on fourteen samples from drill holes DO31 and DO96, Mintex Petrological Solutions, report number: 420314.

Howard, N 2015, 'Geochemistry and hydrothermal alteration at the Mt Rawdon Gold Deposit', AlG Bulletin, vol. 62, pp. 139-146.

Itasca 2017, 'Three-Dimensional Numerical Slope Stability Analyses for the Mt Rawdon Open Pit, mro-stage4v23 Design', computer software.

Jele, R \& Sullivan T, 2016, 'Slope design at Mt Rawdon gold mine', in PM Dight (ed.), Proceedings of the First Asia Pacific Slope Stability in Mining Conference, Australian Centre for Geomechanics, Perth, pp. 353-364.

Pells Sullivan Meynink 2017, 'Stage 4 Design Assessment-Pit Wall Steepening Project', company report, unpublished.

SRK Consulting 2017, Geotechnical and hydrogeological inputs for Mt Rawdon pit slope modelling, powerpoint presentation, unpublished.

Walker, D \& De Bruyn, I 2006, 'Geotechnical blockiness index. a systematic geotechnical mapping method for underground and open pit mines', Proceedings of the 7th Australia-New Zealand Young Geotechnical Professionals Conference, Australian Geomechanics Society, Sydney.

Wines, D 2018, Three-dimensional numerical slope stability analyses for the Mt Rawdon open pit, 'mro_stage4v23' design, Itasca Australia, unpublished. 